\title{
SENTIDO DE PULVERIZAÇÃO EM CULTURAS DE SOJA E FEIJÃO COM PULVERIZADOR DE BARRAS
}

\author{
ALTAIR JUSTINO ${ }^{1}$, LEANDRO MENON ${ }^{2}$, LUCIANO BORA ${ }^{2}$, LUIZ C. GARCIA ${ }^{3}$, \\ CARLOS G. RAETANO ${ }^{4}$
}

\begin{abstract}
RESUMO: O objetivo do experimento foi avaliar o melhor sentido de caminhamento de um pulverizador de barras, montado em três pontos no trator, nas culturas de soja e de feijão. As pulverizações foram orientadas no sentido longitudinal às linhas de semeadura, transversal às linhas de semeadura e no mesmo sentido das linhas de semeadura com os pneus percorrendo locais pré-definidos onde não houve a distribuição de sementes (tramlines). Foram avaliados os componentes de produtividade. Pelos resultados, pode-se observar que não houve diferença significativa quanto aos componentes de produtividade avaliados na cultura da soja quando se variou o sentido da pulverização. Na cultura do feijoeiro, a pulverização no sentido longitudinal apresentou maior produtividade.
\end{abstract}

PALAVRAS-CHAVE: tecnologia de aplicação, produtividade.

\section{TRACK OF SPRAYING IN SOYBEAN AND BEAN CROPS USING A BAR SPRAYER}

\begin{abstract}
The aim of this experiment was to evaluate the best track of a bar sprayer-set in three points of the tractor, in soybean and bean crops. Sprayings were oriented longitudinally to the sowing lines and transversally to the sowing lines with tires passing through pre-determined areas where the sowing was not done (tramlines). Yield factors were evaluated the factors related to yield. Results showed no difference in relation to the components of yield evaluated in the soybean crop even when a variation was done in the track of spraying. However in the bean crop there was a bigger production when track was sprayed longitudinally.
\end{abstract}

KEYWORDS: spraying technology, productivity.

\section{INTRODUÇÃO}

Grande parte dos produtos fitossanitários utilizados na agricultura brasileira são aplicados por meio de pulverizadores de barra. Uma das limitações dessa técnica consiste na redução da produtividade pelo amassamento da cultura. A perda com amassamento na pulverização terrestre é uma desvantagem do sistema quando comparada à aplicação aérea. Porém, quando são feitas várias aplicações na cultura, os danos mecânicos às plantas se diluem durante o processo, uma vez que a máquina passa sempre no mesmo lugar e causa perdas apenas na primeira aplicação. Assim, a pulverização terrestre apresenta menor custo e menor risco de deriva em comparação com a aérea (MATTHEWS, 2000; RAMOS \& PIO, 2003).

Um sistema eficaz é a prática chamada de "tramlines", em que, na época da semeadura da cultura, deixa-se de semear as linhas correspondentes às rodas do trator, ficando, assim, facilmente visíveis para que o operador possa alinhar o trator (WILES \& YAMAOKA, 1981). Para a utilização desse método, exige-se que a largura da semeadora-adubadora e da barra de pulverização sejam correspondentes e também pequenos ajustes na largura dos pneus do trator. Nas plantas das linhas adjacentes aos espaços deixados para a passagem das rodas do trator, podem surgir brotações

\footnotetext{
${ }^{1}$ Eng ${ }^{\text {o }}$ Agrônomo, Prof. Doutor, Departamento de Ciências do Solo e Engenharia Agrícola, UEPG, Ponta Grossa - PR, ajustino@uepg.br

2 Acadêmicos de Agronomia, UEPG, Ponta Grossa - PR.

${ }^{3}$ Eng $^{\mathrm{o}}$ Agrônomo, Pós-Graduando em Proteção de Plantas, UNESP, Botucatu - SP.

${ }^{4}$ Eng ${ }^{0}$ Agrônomo, Prof. Doutor, Departamento de Defesa Fitossanitária, UNESP, Botucatu - SP.

Recebido pelo Conselho Editorial em: 13-4-2006
}

Aprovado pelo Conselho Editorial em: 19-9-2006 
laterais e mais grãos por plantas que minimizam a redução da população de plantas pela pulverização (MATTHEWS, 2000).

O objetivo do experimento foi avaliar o melhor sentido de caminhamento de um pulverizador de barras nas culturas de feijão e de soja. As pulverizações foram orientadas no sentido longitudinal às linhas de semeadura, transversal às linhas de semeadura e no mesmo sentido das linhas de semeadura com os pneus percorrendo locais pré-definidos onde não ocorreu a distribuição de sementes "tramlines".

\section{MATERIAL E MÉTODOS}

O experimento foi instalado na Fazenda Escola "Capão da Onça” da Universidade Estadual de Ponta Grossa, situada no segundo planalto paranaense, município de Ponta Grossa- PR, na safra 2004-2005, em um Cambissolo Háplico distrófico de textura média. O clima da região, segundo Köeppen, é do tipo $\mathrm{Cfb}$, sempre úmido, quente temperado, sem estação seca definida e com geadas freqüentes no inverno. A precipitação anual é em torno de $1.422 \mathrm{~mm}$, sendo janeiro o mês mais chuvoso, com 164,4 mm, e agosto o mês mais seco, com 71,2 mm. As culturas foram implantadas no sistema plantio direto, com $4,8 \mathrm{t} \mathrm{ha}^{-1}$ de palha em cobertura.

A cultivar de soja [Glycine max (L.) Merrill] BRS 134, ciclo médio (maturação entre 126 e 137 dias), hábito de crescimento determinado, foi semeada em 24-11-2004, com semeadoraadubadora de precisão. A máquina foi regulada para distribuir 16 sementes por metro em linhas espaçadas de 0,45 m. A adubação foi de $300 \mathrm{~kg} \mathrm{ha}^{-1}$ da fórmula 0-20-20, e o controle de plantas daninhas ocorreu pela aplicação de propaquizafope $\left(0,6 \mathrm{~L} \mathrm{ha}^{-1}\right.$ de Shogun $\left.240 \mathrm{CE}^{\circledR}\right)+$ óleo mineral parafinico (Assist ${ }^{\circledR}$ a $0,5 \%$ do volume da calda), no dia 27-12-2004, e fomesafem $\left(0,8 \mathrm{~L} \mathrm{ha}^{-1}\right.$ de Flex $\left.{ }^{\circledR}\right)+$ bentazona $\left(1,0 \mathrm{~L} \mathrm{ha}^{-1}\right.$ de Basagran $\left.600^{\circledR}\right)$, no dia 13-1-2005. Os insetos foram controlados pela pulverização de deltamethrina $\left(0,2 \mathrm{~L} \mathrm{ha}^{-1}\right.$ de Decis $\left.25 \mathrm{EC}^{\circledR}\right)$, em 27-12-2004, e beta-ciflutrina $\left(0,05 \mathrm{~L} \mathrm{ha}^{-1}\right.$ de Turbo $\left.^{\circledR}\right)$, nos dias 13-1-2005, $1^{\mathrm{O}}-2-2005$ e 16-2-2005. As aplicações de fungicidas foram preventivas com três aplicações de tebuconazole $\left(0,6 \mathrm{~L} \mathrm{ha}^{-1}\right.$ Folicur $\left.200 \mathrm{EC}^{\circledR}\right)$, nos dias 13-12005, 1ํ-2-2005 e 16-2-2005, e carbendazim $\left(0,4 \mathrm{~L} \mathrm{ha}^{-1}\right.$ de Derosal $\left.500 \mathrm{SC}^{\circledR}\right)$, no dia 16-2-2005.

A cultivar do feijão (Phaseolus vulgaris L.), IPR Uirapuru, grupo comercial preto, porte ereto, ciclo de 86 dias (emergência a colheita), hábito de crescimento arbustivo - indeterminado tipo II, foi semeada em 24-11-2004, com semeadora-adubadora de precisão. A máquina foi regulada para distribuir 17 sementes por metro em linhas espaçadas de $0,45 \mathrm{~m}$ e $300 \mathrm{~kg} \mathrm{ha}^{-1} \mathrm{da}$ fórmula 4-20-20. A adubação foi complementada pela distribuição a lanço de $100 \mathrm{~kg} \mathrm{ha}^{-1}$ de uréia, em 20-12-2004. Os controles de plantas daninhas e pragas seguiram a mesma seqüência aplicada na cultura da soja. As aplicações de fungicidas foram preventivas, com três aplicações de tebuconazol $\left(0,6 \mathrm{~L} \mathrm{ha}^{-1}\right.$ de Folicur $\left.200 \mathrm{EC}^{\circledR}\right)$, nos dias 13-1-2005, 1ํ-2-2005 e 16-2-2005, e hidróxido de fentina $\left(0,4 \mathrm{~L} \mathrm{ha}^{-1}\right.$ de Brestanid $\left.\mathrm{SC}^{\circledR}\right)$, no dia $1^{\mathrm{O}}$ e 16-2-2005.

Os tratamentos consistiram em três técnicas de aplicação de agrotóxicos, sendo elas: 1) pulverização no sentido longitudinal às linhas da cultura, com o posicionamento calculado para que as rodas ocupassem os espaços das entrelinhas, evitando ao máximo danos por amassamento; 2) pulverização no sentido transversal às linhas da cultura, e 3) pulverização no mesmo sentido das linhas da cultura em locais onde houve a interrupção de semeadura daquelas que coincidissem com a bitola do trator "tramlines".

Em todas as técnicas, foi utilizado o pulverizador de barras com engate em três pontos no trator $4 \times 2$, com bitola de $1,84 \mathrm{~m}$. Os pneus no eixo traseiro do trator eram Pirelli 13.6-38 TM $64 / \mathrm{R}^{\circledR}$, com espessura de $0,30 \mathrm{~m}$. O pulverizador apresentava tanque com capacidade para armazenar $800 \mathrm{~L}$ de calda e barra com comprimento de 10,8 m (24 bicos espaçados em 0,45 m). Regulou-se o pulverizador para aplicar $200 \mathrm{~L} \mathrm{ha}^{-1}$ de calda, utilizando-se da ponta XR 11002, pressão de $300 \mathrm{kPa}$ e velocidade de deslocamento de $5,3 \mathrm{~km} \mathrm{~h}^{-1}$.

O delineamento experimental foi o de blocos ao acaso, com três tratamentos e sete repetições. O teste foi constituído de 21 parcelas de 7,0 m de largura por 10,8 m de comprimento, 
correspondendo a 44,0 $\mathrm{m}^{2}$ de área útil para avaliação, devido ao descarte de 1,0 $\mathrm{m}$ de bordadura nas extremidades da parcela.

Os parâmetros avaliados foram: plantas por hectare, vagens por planta, grãos por vagem, massa de 1.000 grãos e produtividade. A quantidade de plantas foi obtida pela contagem dessas em $40 \mathrm{~m}^{2}$ por parcela, e o valor, extrapolado para hectare. A quantidade de vagens por planta foi determinada pela contagem das vagens em 100 plantas, escolhidas ao acaso, por parcela. O número de grãos por vagem foi a média da contagem de 100 vagens, escolhidas ao acaso, por parcela. A massa de 1.000 grãos foi obtida com o auxílio de balança Ohaus Explorer Pro ${ }^{\circledR}$. A produtividade foi determinada pela debulha manual das plantas na área de $10 \mathrm{~m}^{2}$, com umidade dos grãos padronizada em 13\%. O tamanho da amostra foi determinado pela estabilização da média e do desvio-padrão, conforme método proposto por KRANZ (1998).

Os dados foram submetidos à verificação da homocedasticidade das variâncias, pelo teste de Hartley, à análise de variância (ANOVA) pelo teste $\mathrm{F}$ e à comparação de médias pelo teste $\mathrm{t}$, a $5,0 \%$ de probabilidade.

\section{RESULTADOS E DISCUSSÃO}

A técnica de aplicação no sentido longitudinal às linhas de semeadura causou perdas na população de plantas devido ao amassamento provocado pelos pneus do trator durante as pulverizações. Quando as pulverizações foram realizadas no sentido transversal às linhas de semeadura, houve amassamento pelos pneus de até seis plantas por linha, as quais não se recuperaram e evidenciaram a formação de espaços vazios ao longo do percurso. Na técnica "tramlines", deixou-se de semear 8,3\% da quantidade de sementes, em decorrência da supressão de duas linhas de semeadura a cada $10,8 \mathrm{~m}$ (largura da barra do pulverizador) que poderiam sofrer danos mecânicos pelos pneus do trator. Em contrapartida, houve economia de sementes e nãosobreposição das faixas de pulverização pela facilidade de visualização dos espaços para a passagem dos pneus do trator.

O teste de Hartley indicou a homocedasticidade das variâncias, não havendo a necessidade de transformação dos dados para aplicação dos testes estatísticos. O teste $\mathrm{F}$ não foi significativo para blocos, denotando a homogeneidade das condições experimentais. O teste $\mathrm{F}$ não foi significativo, a $5 \%$ de probabilidade, para os tratamentos em todas variáveis em estudo, na cultura da soja (Tabela 1). Portanto, não houve necessidade da aplicação do teste t.

TABELA 1. Média de valores dos componentes de produtividade da soja, BRS 134, em plantio direto, com três técnicas de pulverização.

\begin{tabular}{cccccc}
\hline $\begin{array}{c}\text { Sentido de Pulverização } \\
\text { em Relação às Linhas da } \\
\text { Cultura }\end{array}$ & $\begin{array}{c}\text { População } \\
\left(\text { plantas ha }^{-1}\right)\end{array}$ & $\begin{array}{c}\text { Vagens por } \\
\text { Planta }\end{array}$ & $\begin{array}{c}\text { Grãos por } \\
\text { Vagem }\end{array}$ & $\begin{array}{c}\text { Massa de } \\
1.000 \text { Grãos } \\
(\mathrm{g})\end{array}$ & $\begin{array}{c}\text { Produtividade } \\
\left(\mathrm{kg} \mathrm{ha}^{-1}\right)\end{array}$ \\
\hline Longitudinal & $311.111^{2}$ & $37,3^{2}$ & $2,2^{2}$ & $143,7^{2}$ & $3.669^{2}$ \\
Transversal & 303.333 & 38,3 & 2,3 & 144,3 & 3.856 \\
“Tramlines" & 291.277 & 37,7 & 2,4 & 143,7 & 3.787 \\
Coeficiente de variação & 11,0 & 8,1 & 7,1 & 0,4 & 6,7 \\
\hline
\end{tabular}

${ }^{1}$ Pulverização no mesmo sentido das linhas da cultura com interrupção de semeadura daquelas que coincidisse com a bitola do trator; ${ }^{2} \mathrm{NS}$ - não-significativo pelo teste $\mathrm{F}(\mathrm{P}>0,05)$ para tratamentos e blocos.

As diferenças entre os tratamentos não foram significativas em todas as variáveis testadas. Tal fato pode ser explicado pelas afirmações de MATTHEWS (2000) de que, nas plantas das linhas adjacentes aos espaços deixados pela passagem das rodas do trator, podem surgir brotações laterais e mais grãos por plantas que minimizam a redução da população de plantas pela pulverização.

Ao se analisarem os componentes de produtividade da cultura de feijão (Tabela 2), verificase que o teste F não foi significativo, com um grau de confiança superior a $95 \%$ de probabilidade, 
nas variáveis população, vagens por planta, grãos por vagem e peso de 1.000 grãos. A exceção ocorreu para a variável produtividade.

TABELA 2. Componentes de produtividade do feijão em plantio direto, com três técnicas de pulverização.

\begin{tabular}{cccccc}
\hline $\begin{array}{c}\text { Sentido de Pulverização } \\
\text { em Relação às Linhas da } \\
\text { Cultura }\end{array}$ & $\begin{array}{c}\text { População } \\
\left(\text { plantas ha }^{-1}\right)\end{array}$ & $\begin{array}{c}\text { Vagens por } \\
\text { Planta }\end{array}$ & $\begin{array}{c}\text { Grãos por } \\
\text { Vagem }\end{array}$ & $\begin{array}{c}\text { Massa de } \\
1.000 \text { Grãos } \\
(\mathrm{g})\end{array}$ & $\begin{array}{c}\text { Produtividade } \\
\left(\mathrm{kg} \mathrm{ha}^{-1}\right)\end{array}$ \\
\hline $\begin{array}{c}\text { Longitudinal } \\
\text { Transversal }\end{array}$ & $324.074^{2,3}$ & $8,7^{2,3}$ & 6,0 & $230,2^{2,3}$ & $3.894 \mathrm{a}^{3,4}$ \\
"Tramlines"1 & 326.389 & 7,9 & 5,8 & 225,7 & $3.375 \mathrm{~b}$ \\
Coeficiente de variação & 310.648 & 8,2 & 6,0 & 232,2 & $3.549 \mathrm{~b}$ \\
DMS & 12,2 & 4,0 & 5,8 & 3,2 & 4,8 \\
\hline
\end{tabular}

${ }^{1}$ Pulverização no mesmo sentido das linhas da cultura com interrupção de semeadura daquelas que coincidissem com a bitola do trator; ${ }^{2} \mathrm{NS}$ - não-significativo pelo teste $\mathrm{F}(\mathrm{P}>0,05)$ para tratamentos; ${ }^{3} \mathrm{NS}$ - não-significativo pelo teste $\mathrm{F}$ $(\mathrm{P}>0,05)$ para blocos; ${ }^{4}$ Médias seguidas de mesma letra não diferem pelo teste $\mathrm{t}(\mathrm{P}>0,05)$ para tratamentos.

Assim, devido às características das plantas de feijão, as compensações das plantas (brotações laterais e mais grãos por plantas) adjacentes aos espaços deixados pela passagem das rodas do trator, nos sentidos "transversal" e "tramlines", não foram suficientes para igualar a produtividade obtida pelo método longitudinal.

\section{CONCLUSÕES}

Não houve diferença significativa quanto aos componentes de produtividade avaliados na cultura da soja quando se variou o sentido da pulverização em relação às linhas de semeadura. Na cultura do feijoeiro, a pulverização no sentido longitudinal apresentou maior produtividade.

\section{AGRADECIMENTOS}

Ao programa PIBIC/UEPG, pelo suporte financeiro.

\section{REFERÊNCIAS}

KRANZ, J. Measuring plant disease. In: KRANZ, J.; ROTEM, J. (Ed.). Experimental techniques in plant disease epidemiology. Heidelberg: Springer, 1988. p.35-50.

MATTHEWS, G.A. Pesticide application methods. $3^{\text {rd }}$ ed. London: Blackwell Science, 2000. $432 \mathrm{p}$.

RAMOS, H.H.; PIO, L.C. Tecnologia de aplicação de produtos fitossanitários. In: ZAMBOLIM, L.; CONCEIÇÃO, M.Z.; SANTIAGO, T. O que engenheiros agrônomos devem saber para orientar o uso de produtos fitossanitários. Viçosa: UFV, 2003. p.133-200.

WILES, J.C.; YAMAOKA, R.S. Mecanização. In: IAPAR. Plantio direto no Estado do Paraná. Londrina: IAPAR, 1981. p.59-94. (Circular, 23) 